\title{
BMJ Open Are 'dual users' who smoke and use e-cigarettes interested in using varenicline to stop smoking altogether, and can they benefit from it? A cohort study of UK vapers
}

Peter Hajek, Sarrah Peerbux, Anna Phillips-Waller, Charlotte Smith, Kate Pittaccio, Dunja Przulj

To cite: Hajek P, Peerbux S, Phillips-Waller A, et al. Are 'dual users' who smoke and use e-cigarettes interested in using varenicline to stop smoking altogether, and can they benefit from it? A cohort study of UK vapers. BMJ Open 2019;9:e026642. doi:10.1136/ bmjopen-2018-026642

- Prepublication history for this paper is available online. To view these files, please visit the journal online (http://dx.doi org/10.1136/bmjopen-2018026642).

Received 12 September 2018 Revised 21 January 2019 Accepted 30 January 2019

D Check for updates

(c) Author(s) (or their employer(s)) 2019. Re-use permitted under CC BY-NC. No commercial re-use. See rights and permissions. Published by BMJ.

Health \& Lifestyle Research Unit, Queen Mary University of London, London, UK

Correspondence to Dr Dunja Przulj; d.przulj@qmul.ac.uk

\section{ABSTRACT}

Objectives Smokers who use e-cigarettes (EC) do so mostly to stop smoking, but many continue to use both products. It is not known whether these 'dual users' are interested in stop-smoking medications and whether they can benefit from them.

Setting, participants and measures Dual users were recruited over social media and posted study questionnaire and saliva kits at baseline, 3 and 6 months. Those interested in varenicline were posted the medication and received weekly calls over the first 6 weeks, followed by three calls at fortnightly intervals.

Results Of 204 participants, $124(61 \%, \mathrm{Cl}=54 \%$ to $68 \%)$ expressed interest in receiving varenicline and 80 (39\%, $\mathrm{Cl}=32 \%$ to $45 \%$ ) started varenicline (varenicline users, $\mathrm{VU}$ ). VU were more dependent smokers ( $F=6.2, p=0.01$ ) with higher cigarette consumption $(F=8.7, p<0.01)$ who were using stronger nicotine e-liquids $(F=13.9, p<0.001)$ than dual users not opting for varenicline (varenicline non-users, VN). In terms of abstinence for at least 3 months at the 6-month follow-up, VU were more likely than VN to report abstinence from smoking $(17.5 \%$ vs $4.8 \%, p=0.006, R R=3.6, \mathrm{Cl}: 1.4$ to $9.0)$, vaping ( $12.5 \%$ vs $1.6 \%, p=0.007, R R=7.8, \mathrm{Cl}: 1.7$ to $34.5)$ and both smoking and vaping $(8.8 \%$ vs $0.8 \%, p=0.02$, $\mathrm{RR}=10.9, \mathrm{Cl}: 1.4$ to 86.6). The differences were significant across sensitivity analyses (RRs $=4.9$ to $14.0 ; p=0.02$ to $p<0.001$ at 3 months; RRs $=3.0$ to $14.0 ; p=0.01$ to $p<0.001$ at 6 months). VU reported a greater reduction in enjoyment of vaping by the end of the varenicline use period ( $\mathrm{F}=4.1$, $\mathrm{p}=0.04$ ) and recorded a significantly greater reduction in nicotine intake than $V N$ at 3 months $(F=13.9, p<0.001)$ and 6 months ( $F=26.5, p<0.001)$.

Conclusion Varenicline offered to dual users is likely to promote successful abstinence from both smoking and vaping, although a randomised trial is needed to confirm this. Among dual users who want to stop smoking, there seems to be a high level of interest in smoking-cessation treatments.

\section{BACKGROUND}

Smokers who use e-cigarettes (EC) do so mostly to stop or reduce smoking. For example, among US adult EC users, 85\%
Strengths and limitations of this study

- The main strength is that this was the first study of this kind and provides new insights into dual users' interest in stop-smoking treatment and its effects.

- The main limitation is that his was not a randomised comparison.

- Recruitment via social media may have attracted a sample with characteristics that are not representative of the wider population of dual users and the generalisability of the results is thus unclear.

used EC to stop smoking or reduce health risks of smoking. ${ }^{1}$ Some of the smokers who initiate EC use (vaping) stop smoking soon after starting to use EC, others abandon vaping, and some use both EC and cigarettes for various periods of time. ${ }^{2}{ }^{3}$ In these "dual users', EC seem to provide rewards that are sufficient to maintain vaping, but not sufficient to stop smoking.

Compared with smokers who switch to vaping completely, dual users were reported to have lower education and income ${ }^{4}$ and to be more likely to have smoking peers. ${ }^{5}$ They recourse to cigarettes in stressful situations and when rapid nicotine uptake is required, ${ }^{67}$ but also in hedonic situations. ${ }^{8}$ They also typically have a history of failed quit attempts. ${ }^{9}$ It seems likely that dual users tend to be more dependent smokers who wish to stop smoking, but are finding smoking cessation difficult.

As dual users are typically interested in stopping smoking altogether, a question arises whether they could benefit from using stop-smoking medications. No data exist on whether dual users are interested in stopsmoking treatments and on their reactions 
to them. The present study was set up to collect the first information on this topic.

In this exploratory study, we examined what proportion of dual users are interested in using varenicline, and what impact such treatment has on smoking and vaping behaviour and on nicotine intake. Separately from these objectives, the study is also monitoring changes in vaping and smoking in dual users over an extended period of time, together with attitudinal and other measures. These results will be reported separately.

\section{METHODS}

\section{Aims}

To assess interest among dual users in using varenicline to stop smoking altogether and to monitor changes in smoking and vaping in those who did and those who did not opt for varenicline treatment.

\section{Study design}

Cohort follow-up study.

\section{Participants}

Participants were recruited via Facebook advertising and leaflets between November 2015 and January 2017. The patient information sheet explained that some smokers who start to use EC continue using conventional cigarettes (CC) as well and that little is known about the way such use develops over time. It is also not clear how many dual users succeed in stopping smoking altogether and what proportion is interested in receiving stop-smoking medication to do so. Dual users are being invited to take part in the study to clarify these issues.

Dual users were eligible if they smoked at least 10 cigarettes a day for more than 1 year prior to initiating EC use; have been using EC for at least 1 month; were using both products (EC and CC) separately or concurrently for at least 3 days a week; and were interested in stopping smoking altogether.

\section{Procedures}

Potential participants were screened over the telephone or email. If eligible, they were posted study details and the consent form, together with the baseline questionnaire and saliva kit. When the study team received the questionnaire and saliva samples, the medical record part of the questionnaire of participants interested in receiving varenicline was screened to confirm that they can be provided with the medication. All participants interested in using varenicline were eligible for receiving it. The participants were then called to confirm that they remain interested in using the medication and if they were, they were informed that the medication (the initial 4-week supply) is being posted to them; and they were asked to call the study team on receipt of the medication and before they started using it.

When participants received the medication and called back, they were guided in setting up their target quit day
(TQD) 1-2 weeks later and in starting to use the medication. They then received brief telephone calls weekly over the first 6 weeks, followed by three calls at fortnightly intervals. The content of the calls followed the standard practice of telephone support at the participating stopsmoking clinic, that is, monitoring medication use and whether further supplies are needed, and providing motivational support. The calls also collected data on CC and EC use. Medication was posted as needed for up to 3 months. Participant uptitrated varenicline use from $1 / 2 \mathrm{mg}$ per day for three days through $1 / 2 \mathrm{mg}$ twice per day for the rest of the first week and to $1 \mathrm{mg}$ twice a day for the rest of the course, as per product labelling.

All participants (whether asking for varenicline or not) were contacted by telephone or email at 3 and 6 months. Saliva sampling kits and study questionnaires were posted to them with a request to call the study team when the materials were received. The package included $£ 20$ at baseline and $£ 10$ at 3 and 6 months as a compensation for participant's effort and time.

\section{Stop-smoking medication}

Varenicline was provided by the manufacturer Pfizer. The dosing was as per product labelling.

\section{Measures}

The baseline questionnaire recorded demographic details, health status, smoking history and cigarette dependence assessed via Fagerstrom test of cigarette dependence $(\mathrm{FTCD}),{ }^{10}$ vaping history and interest in using varenicline.

Participants who opted for varenicline were asked about their varenicline use (used as prescribed: yes or no) and about their smoking and vaping each week.

At 3-month and 6-month follow-ups, all participants were asked about average number of cigarettes smoked per day and EC cartridges or $\mathrm{mL}$ of e-liquid used per day.

Participants who were still smoking and/or vaping were asked about their enjoyment of smoking and vaping, that is, "How much do you enjoy smoking/vaping?" on a scale of $1-10$, where $1=$ not at all and $10=$ extremely.

Salivary samples were collected at baseline and at 3-month and 6-month follow-ups and assayed for cotinine and anabasine at ABS Laboratories, UK.

Table 1 shows the schedule of assessments.

\section{Sample size and data analysis}

No data exist on the level of interest among dual users in receiving assistance in smoking cessation or on the effects of varenicline in this population. We opted for recruiting at least 200 dual users to obtain key estimates with reasonable confidence intervals. For instance, if $10 \%$ of the respondents would be interested in using varenicline, this sample size would provide $95 \%$ probability of the true population proportion falling within the range of $5.8 \%-14.1 \%$.

Changes in smoking and vaping variables, and differences between subgroups of participants who did and 


\begin{tabular}{llll} 
Table 1 Schedule of assessments & & \\
\hline & Baseline & 3 Months & 6 Months \\
\hline Measures/procedures & & & \\
Baseline questionnaire & $X$ & & \\
Interest in receiving varenicline & $\mathrm{X}$ & & $\mathrm{X}$ \\
Salivary cotinine and anabasine & $\mathrm{X}$ & $\mathrm{X}$ & $\mathrm{X}$ \\
Smoking/vaping status/rate* & $\mathrm{X}$ & $\mathrm{X}$ & $\mathrm{X}$ \\
$\begin{array}{l}\text { Enjoyment of smoking and } \\
\text { vaping* }^{*}\end{array}$ & $\mathrm{X}$ & $\mathrm{X}$ & \\
\hline
\end{tabular}

*Measures collected also at each phone call with participants opting for treatment.

did not opt for varenicline treatment, were assessed using analysis of variance for continuously distributed endpoints and chi-square tests for categorical endpoints. Risk ratios and 95\% CIs were also calculated for abstinence outcomes.

The primary outcome was self-reported abstinence from smoking (not a single puff) for at least 3 months at the 6 months' follow-up. We also assessed abstinence from vaping and from both smoking and vaping. As sensitivity analyses, we assessed self-reported abstinence over the previous month and over the previous 7 days. We did not include abstinence measures linked to a TQD because only the varenicline users were asked to set up a TQD. Participants lost to follow-up were included as non-abstainers. Missing data for other variables were not imputed.

\section{Patient and public involvement}

The study was informed by discussions with participants at our previous trials and with patients attending our clinics.

\section{RESULTS}

We did not turn down responders who contacted us after the final advertising wave and recruited 204 participants in total. The participants' flow is shown in figure 1.

Of the 204 participants, $124(61 \% ; 95 \%$ CI $=54 \%$ to $68 \%)$ expressed the initial interest in receiving varenicline, 85 ( $42 \%$; $95 \% \mathrm{CI}=35 \%$ to $48 \%$ ) were reached (by text, phone or e-mail), confirmed their interest and were sent the medication and 80 (39\%; 95\% CI=32\% to 45\%) started treatment. Of the five who received the medication but decided not to start using it, three were experiencing stressful events and felt this was not the right time to start stop-smoking treatment, one stopped smoking on their own in the meantime, and one lost the medications and later dropped out of the study.

Table 2 shows baseline characteristics of the subgroups that started and did not start varenicline use. Dual users who opted for varenicline were more dependent smokers with higher cigarette consumption who were using higher nicotine strength e-liquids.

Table 3 shows the proportions of participants who stopped smoking, vaping or both at each time point.

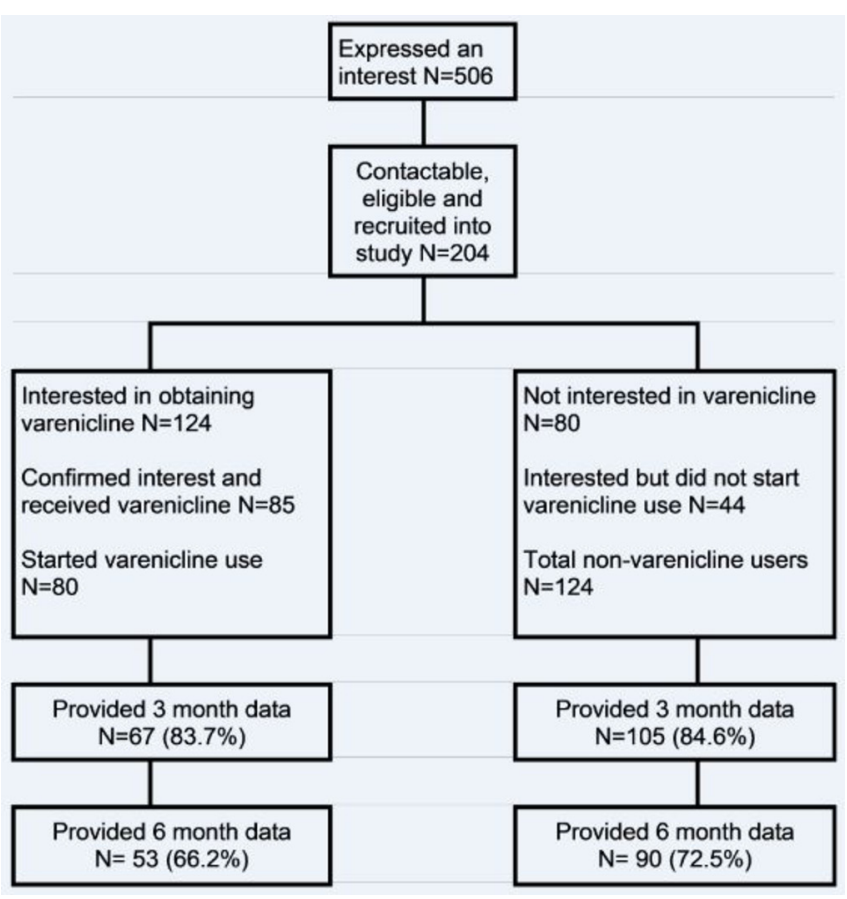

Figure 1 Participant flow chart.

Participants who used varenicline were more likely to stop smoking, stop vaping or stop both at all time points.

In the analysis above, 44 people who expressed interest in varenicline but did not start using it were included among non-users. To examine a possibility that this subsample may have been people less likely to modify their smoking and vaping, we conducted a sensitivity analysis with the 44 participants excluded. The results were virtually identical.

We were able to verify self-reports of abstinence in participants who claimed to have stopped both smoking and vaping via cotinine assays (see table 3 ). Including participants who failed validation as non-abstainers did not change the results much ( $R R=10.9$ to $R R=14.0$; $\mathrm{p}=0.02$ to $\mathrm{p}=0.01$ ).

Table 4 shows varenicline use among all participants who started the medication and among those who were abstinent from smoking at 3 months, by the end of the varenicline use period. Adherence to varenicline treatment was relatively high, with even some of the smokers who failed to quit completely continuing varenicline use for the full 3 months.

Table 5 shows changes in enjoyment of vaping and smoking by the end of the varenicline use period at 3 months in participants who were still using their nicotine products and who provided the ratings. The varenicline group recorded bigger reductions in enjoyment of both smoking and vaping, but this only reached significance for reduced enjoyment of vaping.

Figures 2 and 3 show changes in cotinine levels in the two groups at 3 and 6 months, respectively. We obtained usable cotinine samples from 135 participants at 3 months and 115 at 6 months. Varenicline use was associated with significantly larger reduction in nicotine intake at both 
Table 2 Baseline characteristics of participants who did and did not use varenicline

\begin{tabular}{|c|c|c|c|}
\hline & $\begin{array}{l}\text { Used varenicline } \\
(n=80)\end{array}$ & $\begin{array}{l}\text { Did not use varenicline } \\
(\mathrm{n}=124)\end{array}$ & Difference \\
\hline Age (SD) & $33.6(11.6)$ & $30.4(11.2)$ & $F=3.8, p=0.05$ \\
\hline$\%$ women & $28.7 \%$ & $30.6 \%$ & $\begin{array}{l}\chi^{2}=0.08 \\
p=0.77\end{array}$ \\
\hline$\%$ in full-time employment & $72.5 \%$ & $75.0 \%$ & $\begin{array}{l}\chi^{2}=0.01 \\
\mathrm{P}=0.92\end{array}$ \\
\hline FTCD (SD) & $4.9(2.2)$ & $4.1(2.1)$ & $F=6.2, p=0.01$ \\
\hline Ethnicity (\% White British) & $93.8 \%$ & $90.3 \%$ & $\begin{array}{l}\chi^{2}=0.8 \\
P=0.39\end{array}$ \\
\hline CPD (SD) now & $11.6(5.1)$ & $9.2(6.0)$ & $\mathrm{F}=8.7, \mathrm{P}<0.01$ \\
\hline CPD (SD) before starting to vape & $20.7(10.1)$ & $22.4(8.6)$ & $F=1.7, P=0.20$ \\
\hline $\begin{array}{l}\text { Enjoyment of } \\
\text { smoking (SD) }\end{array}$ & $6.2(2.4)$ & $6.1(2.5)$ & $\begin{array}{l}F=0.09 \\
P=0.77\end{array}$ \\
\hline Enjoyment of vaping (SD) & $7.2(2.3)$ & $7.5(2.3)$ & $\begin{array}{l}F=0.69 \\
P=0.41\end{array}$ \\
\hline Months of vaping (SD) & $18(13.6)$ & $22(36.9)$ & $\begin{array}{l}F=1.01 \\
P=0.32\end{array}$ \\
\hline E-liquid nicotine concentration $(\mathrm{mg} / \mathrm{mL})(\mathrm{SD})$ & $13.9(9.9)$ & $9.3(7.4)$ & $F=13.9, p<0.001$ \\
\hline Using refillable EC (\%) & $95.0 \%$ & $91.9 \%$ & $\begin{array}{l}\chi^{2}=3.4 \\
P=0.19\end{array}$ \\
\hline
\end{tabular}

CPD, cigarettes per day; EC, e-cigarette; FTCD, Fagerstrom test of cigarette dependence.

3 and 6 months $(\mathrm{F}=13.9, \mathrm{p}<0.001$ and $\mathrm{F}=26.5, \mathrm{p}<0.001$, respectively). Among the subsamples of participants who continued to smoke, the varenicline group reduced their nicotine intake while the other group increased it, but the between group difference was only significant at 6 months $(\mathrm{F}=17.9, \mathrm{p}<0.001)$.

We obtained usable anabasine samples from 126 participants at 3 months and 109 at 6 months, but salivary

Table 3 Cessation of smoking and vaping in participants who did and did not use varenicline

$\begin{array}{lll}\begin{array}{l}\text { Used varenicline } \\ (n=80)\end{array} & \begin{array}{l}\text { Did not use varenicline } \\ (n=124)\end{array} & P \text { value, RR and } 95 \% \mathrm{CI}\end{array}$

\begin{tabular}{|c|c|c|c|}
\hline \multicolumn{4}{|l|}{ Stopped smoking } \\
\hline $3 \mathrm{M}-$ past 7 days & $43.8 \%(35)$ & $8.9 \%(11)$ & $\mathrm{P}<0.001, \mathrm{RR}=4.9(2.7$ to 9.1$)$ \\
\hline $3 \mathrm{M}$ - past 30 days & $32.5 \%(26)$ & $5.6 \%(7)$ & $\mathrm{P}<0.001, \mathrm{RR}=5.8$ (2.6 to 12.6 ) \\
\hline $6 \mathrm{M}$ - past 7 days & $31.3 \%(25)$ & $10.5 \%(13)$ & $\mathrm{P}<0.001, \mathrm{RR}=3.0(1.6$ to 5.5$)$ \\
\hline $6 \mathrm{M}$ - past 90 days $\dagger$ & $17.5 \%(14)$ & $4.8 \%(6)$ & $P=0.006, R R=3.6(1.4$ to 9.0$)$ \\
\hline \multicolumn{4}{|l|}{ Stopped vaping } \\
\hline $3 \mathrm{M}$ - past 7 days & $23.8 \%(19)$ & $3.2 \%(4)$ & $\mathrm{P}<0.001, \mathrm{RR}=7.4$ (2.6 to 20.9) \\
\hline $3 \mathrm{M}$ - past 30 days & $18.7 \%(15)$ & $1.6 \%(2)$ & $\mathrm{P}<0.001, \mathrm{RR}=11.6(2.7$ to 49.5$)$ \\
\hline $6 \mathrm{M}$ - past 7 days & $25 \%(20)$ & $3.2 \%(4)$ & $\mathrm{P}<0.001, \mathrm{RR}=10.3$ (3.2 to 33.6) \\
\hline $6 \mathrm{M}$ - past 90 days & $12.5 \%(10)$ & $1.6 \%(2)$ & $\mathrm{P}=0.007, \mathrm{RR}=7.8(1.7$ to 34.5$)$ \\
\hline \multicolumn{4}{|l|}{ Stopped both* } \\
\hline $3 \mathrm{M}-$ past 7 days & $11.3 \%(9)$ & $0.8 \%(1)$ & $\mathrm{P}=0.01, \mathrm{RR}=14.0(1.8$ to 108.1$)$ \\
\hline $3 \mathrm{M}$ - past 30 days & $8.8 \%(7)$ & $0.8 \%(1)$ & $\mathrm{P}=0.02 \mathrm{RR}=10.9$ (1.4 to 86.6$)$ \\
\hline $6 \mathrm{M}-$ past 7 days & $11.3 \%(9)$ & $0.8 \%(1)$ & $P=0.01, R R=14.0$ (1.8 to 108.1$)$ \\
\hline $6 \mathrm{M}$ - past 90 days & $8.8 \%(7)$ & $0.8 \%(1)$ & $\mathrm{P}=0.02, \mathrm{RR}=10.9(1.4$ to 86.6$)$ \\
\hline
\end{tabular}

*Only participants who passed cotinine validation are included.

†Primary outcome. 
Table 4 Adherence to varenicline treatment (N, \%)

\begin{tabular}{llll}
$\begin{array}{l}\text { Week post- } \\
\text { TQD }\end{array}$ & $\begin{array}{l}\text { All } \\
\text { varenicline } \\
\text { users (n=80) }\end{array}$ & $\begin{array}{l}\text { Quitters at } \\
\text { 3 months* } \\
(\mathbf{n = 2 6 )}\end{array}$ & $\begin{array}{l}\text { Non-quitters } \\
(\mathbf{n = 5 4 )}\end{array}$ \\
\hline 1 & $46(57.5 \%)$ & $22(84.6 \%)$ & $24(44.4 \%)$ \\
\hline 2 & $41(51.2 \%)$ & $20(76.9 \%)$ & $21(38.8 \%)$ \\
3 & $30(37.5 \%)$ & $16(61.5 \%)$ & $14(25.9 \%)$ \\
\hline 4 & $31(38.7 \%)$ & $15(57.6 \%)$ & $16(29.6 \%)$ \\
\hline 6 & $23(28.7 \%)$ & $15(57.6 \%)$ & $8(14.8 \%)$ \\
\hline 10 & $14(17.5 \%)$ & $8(30.7 \%)$ & $6(11.1 \%)$ \\
12 & $12(15.0 \%)$ & $7(26.9 \%)$ & $5(9.2 \%)$ \\
\hline
\end{tabular}

${ }^{*}$ No smoking in last 30 days.

$\mathrm{TQD}$, target quit day.

anabasine turned out not be a sensitive enough marker, with a very narrow range of very low values and a number of zero readings in participants who reported regular smoking (varenicline users and non-users had a drop in anabasine levels of $0.5[\mathrm{SD}=1.7]$ vs $0.3[\mathrm{SD}=1.8] \mathrm{ng} / \mathrm{mL}$, $\mathrm{p}=0.51$ at 3 months; and $0.3[\mathrm{SD}=2.6]$ vs $0.1[\mathrm{SD}=2.3] \mathrm{ng} /$ $\mathrm{mL}, \mathrm{p}=0.59$ at 6 months).

\section{DISCUSSION}

A large proportion of dual users (61\%) expressed interest in using varenicline to help them stop smoking altogether, with 39\% starting treatment. Compared with the rest of the sample, dual users who used varenicline had much higher rates of quitting smoking as well as quitting vaping.

The substantial interest among dual users in using a stop-smoking medication was unexpected. We assumed initially that because dual users opted for EC in preference to licensed medications (that are offered by the National Health Service and local stop-smoking services virtually free in the UK), they will show limited interest in using them. The majority however were interested. Attempts at health behaviour changes are often characterised by gaps between intentions and actions and in this case, over a third of those who initially expressed interest

\begin{tabular}{|c|c|c|c|}
\hline & $\begin{array}{l}\text { Used } \\
\text { varenicline }\end{array}$ & $\begin{array}{l}\text { Did not use } \\
\text { varenicline }\end{array}$ & Difference \\
\hline $\begin{array}{l}\text { Mean difference in } \\
\text { enjoyment of vaping } \\
\text { from baseline (SD) }\end{array}$ & $\begin{array}{l}-0.8(2.2) \\
n=44\end{array}$ & $\begin{array}{l}-0.2(1.5) \\
n=99\end{array}$ & $\begin{array}{l}F=4.1 \\
P=0.04\end{array}$ \\
\hline $\begin{array}{l}\text { Mean difference in } \\
\text { enjoyment of smoking } \\
\text { from baseline (SD) }\end{array}$ & $\begin{array}{l}-1.2(2.9) \\
\mathrm{n}=27\end{array}$ & $\begin{array}{l}-0.5(2.1) \\
n=90\end{array}$ & $\begin{array}{l}F=1.7 \\
P=0.19\end{array}$ \\
\hline
\end{tabular}

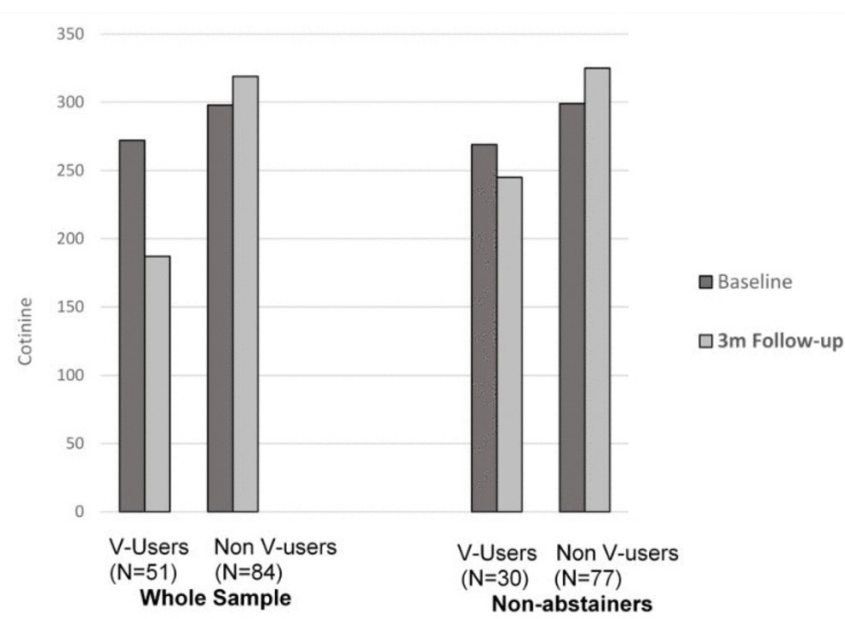

Figure 2 Change from baseline to 3 months in cotinine levels $(\mathrm{ng} / \mathrm{mL})$ in participants who used and did not use varenicline. Non-V-users, did not use varenicline; V-Users, varenicline user.

did not progress to the actual use. This however still left $39 \%$ of the sample initiating varenicline treatment.

Dual users who started varenicline treatment were heavier smokers with higher tobacco dependence who were using higher strength nicotine liquids than the rest of the sample. It seems likely that this subsample was finding reducing or quitting smoking more difficult than the rest of the cohort, but they may have also been more motivated to do so. A randomised trial would be needed to control for such variables. It is possible that the effect of varenicline would be even stronger because the groups would be matched for dependence, but it could also be weaker if the current results were influenced by differences in motivation to quit smoking.

The difference in quitting nicotine use between participants who did and those who did not use varenicline was remarkably large ( $R R=3.6$ for stopping smoking, $\mathrm{RR}=7.8$ for stopping vaping and $\mathrm{RR}=10.9$ for stopping both for at least the past 3 months at the 6-month follow-up).

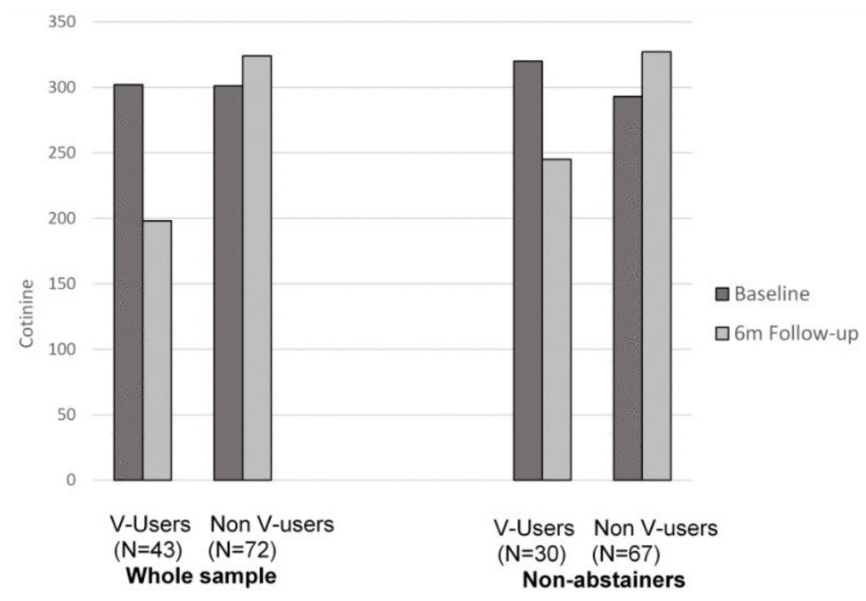

Figure 3 Change from baseline to 6 months in cotinine levels $(\mathrm{ng} / \mathrm{mL})$ in participants who used and did not use varenicline. Non-V-users, did not use varenicline; V-users, varenicline user. 
It was hypothesised that one of the key moderators of the effect of varenicline on stopping smoking is its effect on reducing urges to smoke. ${ }^{11}$ We were unable to monitor withdrawal symptoms in non-vareincline users during the acute withdrawal phase, but we collected ratings of enjoyment of smoking and vaping at different time points. At the end of the varenicline use period at 3 months, the varenicline group was reporting a significantly greater reduction in enjoyment of vaping, while the difference in reduction of enjoyment of smoking did not reach statistical significance. The varenicline effect on vaping cessation also appeared stronger than its effect on cessation of smoking. The data tally with the previous findings suggesting that the medication exerts its influence in part at least by reducing the reward from nicotine. ${ }^{11}$

This is further supported by the finding that varenicline use was associated with a reduction in nicotine intake, indexed by salivary cotinine, at all time points. An activity that generates less reward can be expected to subside. A recent trial of nicotine replacement 'preloading' (use of nicotine patches for 4 weeks while participants continue to smoke ad-lib) identified the reduction in urges to smoke before and after stopping smoking and a reduction in smoke intake as mediators of the treatment effect on abstinence. ${ }^{12} 13$ This tallies closely with the present findings.

The finding that the varenicline group showed a reduction in nicotine intake in non-abstainers at 6 months is more difficult to interpret. The experience with varenicline may have had some kind of on-going impact that continued even after the medication ceased, but this could also be a chance finding.

The main limitation of the study is that this was not a randomised comparison. As discussed above, dual users opting for varenicline may have been more motivated to stop smoking than others, although interest in stopping smoking was the inclusion criterion. Participants in the varenicline group also received weekly support and this could have made them more likely to respond to follow-up calls and less likely to drop out than the rest of the sample. This however was not the case, the follow-up rates were in fact slightly higher in the non-varenicline group. The weekly support calls may have boosted the quit rate in the varenicline group, although telephone support on its own has been shown to have only modest long-term effects. ${ }^{14}$ We were able to validate smoking status in people who claimed to have stopped both smoking and vaping via salivary cotinine, but salivary anabasine turned out not be an accurate enough measure. In dual users, nicotine and its metabolites cannot be used to verify abstinence from smoking, but future studies may consider using urinary index of exposure to tobacco-specific nitrosamine NNK for this purpose.${ }^{15}$ With no biochemical confirmation of abstinence from smoking in EC users, the study relied on self-reports and this could have introduced a bias, although we did detect significant differences between the groups in cotinine levels. Another possible source of bias that may have affected our results is that only the varenicline group set up a formal quit date. This would have a major influence on the usual indicators of sustained abstinence rates timed from the TQD because only one group was asked to quit on that day. The varenicline effect however was also present when looking at abstinence during months 3 to 6 , and also when looking at abstinence for just the past 7 days at 6 months. In the sample of people intending to stop smoking, such measures that are not linked to an early quit date should be less vulnerable to any such effect. The issue of having or not having a TQD could also be expected to have little impact on EC use because participants were not asked to stop or reduce vaping. The fact that varenicline use was associated with a similar effect size with regard to quitting vaping mitigates the concern. Loss to follow-up represents another study limitation. Finally, this was not a random sample. Recruitment via social media may have attracted a sample with characteristics that are not representative of the wider population of dual users and the generalisability of the results is thus unclear.

In summary, varenicline offered to dual users is likely to promote successful abstinence from both smoking and vaping, although a randomised trial is needed to confirm the finding. Among dual users who intend to stop smoking altogether, there seems to be a high level of interest in smoking cessation treatments.

Contributors All authors (PH, DP, SP, AP-W, CS and KP) contributed to the planning and conduct of the work, and $\mathrm{DP}, \mathrm{PH}, \mathrm{KP}$ and SP contributed to the reporting of the work. PH and DP are responsible for the overall content as guarantors. The guarantors accept full responsibility for the work and/or the conduct of the study, had access to the data and controlled the decision to publish. The corresponding author attests that all listed authors meet authorship criteria and that no others meeting the criteria have been omitted.

Funding The study was funded by an investigator-initiated grant from Pfizer. The funder was not involved in the study design, conduct, or data analysis.

Competing interests All authors declare: support from Pfizer for the work; no financial relationships with any organisations that might have an interest in the submitted work in the previous three years; and PH has provided consultancy to manufacturers of stop-smoking medications.

Patient consent for publication Not required.

Ethics approval The study was approved by the NHS Research Ethics Committee, England (reference number: 15/WM/0334).

Provenance and peer review Not commissioned; externally peer reviewed.

Data sharing statement Data are available upon request from the corresponding author.

Open access This is an open access article distributed in accordance with the Creative Commons Attribution Non Commercial (CC BY-NC 4.0) license, which permits others to distribute, remix, adapt, build upon this work non-commercially, and license their derivative works on different terms, provided the original work is properly cited, appropriate credit is given, any changes made indicated, and the use is non-commercial. See: http://creativecommons.org/licenses/by-nc/4.0/.

\section{REFERENCES}

1. Patel D, Davis KC, Cox S, et al. Reasons for current E-cigarette use among U.S. adults. Prev Med 2016;93:14-20.

2. Etter JF. Electronic cigarettes: a survey of users. BMC Public Health 2010;10:231.

3. Etter JF, Bullen C. Electronic cigarette: users profile, utilization, satisfaction and perceived efficacy. Addiction 2011;106:2017-28. 
4. Schoren $\mathrm{C}$, Hummel K, Vries H. Electronic cigarette use: comparing smokers, vapers, and dual users on characteristics and motivational factors. Tob Prev Cessat 2017;3.

5. Cooper M, Case KR, Loukas A, et al. E-cigarette dual users, exclusive users and perceptions of tobacco products. Am J Health Behav 2016;40:108-16.

6. Adriaens K, Van Gucht D, Baeyens F. Differences between dual users and switchers center around vaping behavior and its experiences rather than beliefs and attitudes. Int $J$ Environ Res Public Health 2017;15:12.

7. Pokhrel P, Herzog TA, Muranaka N, et al. Contexts of cigarette and e-cigarette use among dual users: a qualitative study. BMC Public Health 2015;15:859.

8. Rass O, Pacek LR, Johnson PS, et al. Characterizing use patterns and perceptions of relative harm in dual users of electronic and tobacco cigarettes. Exp Clin Psychopharmacol 2015;23:494-503.

9. Maglia M, Caponnetto P, Di Piazza J, et al. Dual use of electronic cigarettes and classic cigarettes: a systematic review. Addiction Research and Theory 2017:1-9.
10. Fagerström K. Determinants of tobacco use and renaming the FTND to the fagerstrom test for cigarette dependence. Nicotine Tob Res 2012;14:75-8.

11. Hajek P, McRobbie HJ, Myers KE, et al. Use of varenicline for 4 weeks before quitting smoking: decrease in ad lib smoking and increase in smoking cessation rates. Arch Intern Med 2011;171:770-7.

12. Preloading Investigators. Effects on abstinence of nicotine patch treatment before quitting smoking: parallel, two arm, pragmatic randomised trial. BMJ 2018;361:k2164.

13. Hajek P, Lewis $S$, Munafo M, et al. Mediators of the effect of nicotine pre-treatment on quitting smoking. Addiction. In Press. 2018;113:2280-9.

14. Stead LF, Perera R, Lancaster T. Telephone counselling for smoking cessation. Cochrane Database Syst Rev 2006:CD002850.

15. Goniewicz ML, Smith DM. Are Some E-Cigarette Users "Blowing Smoke"?: assessing the accuracy of self-reported smoking abstinence in exclusive E-cigarette users. Nicotine \& Tobacco Research 2018;84:nty085. 